\title{
A Dança Imanente e seus Atravessamentos Educacionais: Reflexões acerca de uma práxis artístico-educativa na Companhia Mo- derno de Dança
}

\author{
Luiza Monteiro e Souza \\ Universidade Federal do Pará - UFRGS, Belém, Brasil \\ E-mail: Imonteiro@ufpa.br
}

Resumo

Este texto apresenta atravessamentos da área da Dança com a Educação. No bojo da reflexão encontra-se a dança imanente, práxis artística da Companhia Moderno de Dança - CMD, coletivo de Belém do Pará. Constam como referências principais da escrita a dança imanente (MENDES, 2010) e questões em educação (FREIRE, 1996), alinhados a abordagens que tratam sobre corpo, imanência, ensino e aprendizagem em dança e processo de criação. A escrita parte dos processos artísticos-formativos da CMD, observando que a dança imanente é atravessada por questões educacionais para além de considerações utópicas acerca de práticas em dança e educação. Como objetivos, intenta-se aprofundar a argumentação teórica em dança imanente; dialogar com abordagens contemporâneas a respeito da educação; possibilitar dobras e outros olhares para as questões artísticas e formativas na área da dança/arte. O presente texto também intende possibilitar o alargamento dos sentidos para a assunção de que qualquer conhecimento em dança pode e deve ser reconhecido e legitimado por seus fazedores na qualidade de explicitamente educativos.

Palavras-chave

Dança imanente. Companhia Moderno de Dança. Educação.
Abstract

This text presents crossings from the area of Dance with Education. In the core of reflection is the immanent dance, artistic praxis of the Companhia Moderno de Dança - CMD, collective of Belém do Pará. The main references of the writing are the immanent dance (MENDES, 2010) and issues in education (FREIRE, 1996), aligned to approaches that deal with body, immanence, teaching and learning in dance and creation process. The writing is based on the artistic-formative processes of the CMD, observing that immanent dance is crossed by educational issues that go beyond utopian considerations about practices in dance and education. As objectives, it is tried to deepen the argumentation in immanent dance; dialogue with contemporary approaches regarding education; to provide folds and other looks for the artistic and formative issues in the area of dance / art. Moreover, this text intends to allow the widening of the senses for the assumption that any knowledge in dance can and should be recognized and legitimized by its makers as explicitly educational.

Keywords

Immanent dance. Companhia Moderno de Dança. Education. 
Introdução

\section{Experiências em dança na relação com a educação}

A Companhia Moderno de Dança CMD é um coletivo artístico fundado em novembro de 2002 a partir do trabalho do grupo coreográfico do Colégio Moderno, em Belém do Pará. Após iniciarem os processos para ingressar na universidade, alguns bailarinos, em parceria com o professor Gláucio Sapucahy (diretor executivo da companhia) e a professora

Ana Flávia Mendes (diretora artística da companhia), fundaram a companhia para dar prosseguimento às pesquisas e produções na área da dança até então vivenciadas. Naquele momento os artistas fundadores já sofriam os primeiros atravessamentos educacionais na instauração de seu coletivo artístico, tendo em vista que este era concebido e encontrava suportes no universo escolar. De acordo com Mendes,

A companhia, ainda que não se caracterize como grupo institucional, funciona com o apoio do Colégio Moderno, especialmente de sua Diretora Pedagógica, professora Marlene Vianna. Trata-se de uma companhia vinculada ao Colégio Moderno por meio do empréstimo do espaço físico da instituição, além do vínculo histórico e emocional, uma vez que a maioria dos integrantes estudou nesta instituição (MENDES, 2010, p. 36) ${ }^{1}$.

Com mais de quinze anos de existência e inserida no contexto artístico da produção de poéticas contemporâneas em dança, a CMD tem sua missão voltada para a pesquisa, criação e concepção de movimen-

\footnotetext{
1 Esta citação faz referência ao período de criação da companhia. Atualmente, a CMD não possui mais vínculo institucional com o Colégio Moderno, tendo como lócus de produção artística seu próprio espaço, o Espaço Companhia Moderno de Dança.
}

tos/danças. Independente do eixo temático, seus trabalhos exploram sobretudo a invenção de movimentos por meio do corpo que dança na perspectiva de ampliar sua práxis artística, intitulada de dança imanente, na qualidade de indutora para a construção de poéticas que se proponham a evidenciar o corpo do artista como lócus de pesquisa, experimentação e criação da dança.

As primeiras produções bibliográficas presentes neste percurso foram lançadas no ano de 2010, quando publicou-se a coleção bibliográfica Processos criativos em companhia ${ }^{2}$, composta de três volumes: 1) Gesto transfigurado (dissertação de mestrado em artes cênicas de Ana Flávia Mendes); 2) Dança imanente (tese de doutorado em artes cênicas de Ana Flávia Mendes); 3) Abordagens criativas na cena (coletânea de textos de autoria dos dançarinos do grupo) ${ }^{3}$.

Duas das publicações supracitadas tiveram como indutores processos criativos da CMD. No período de 2005 a 2008, anos do doutoramento de Ana Flávia, foi cunhada a noção de dança imanente cujos contornos vêm se delineando como práxis artística da companhia, e também se encontra aplicada a outros contextos de ensino e aprendizagem em artes. Esta noção propõe focalizar o olhar do artista no corpo com a perspectiva do reconhecimento de que o movimento dançado pode surgir do desvelar individual e coletivo em imersão nos mais diversos processos criativos.

\footnotetext{
2 Resultado de um projeto contemplado pela FUNARTE no edital Bolsa de Estímulo à Produção Crítica em Dança de 2008.
3 Em 2019, a CMD lançará mais 3 volumes da coleção. Pre- miado pelo prêmio de Dança Klauss Viana 2015, o volume 4 intitulado de Experimentações em Dança Imanente é resultado de minha pesquisa de mestrado junto ao Programa de Pós-Gra- duação em Artes, PPGARTES/ICA/UFPA. O volume 5, $A$ dança imanente no ensino e criação em artes cênicas é resultado do pós-doutorado de Ana Flávia Mendes e, o volume 6, intitulado Ensaios de uma companhia (Pós) Moderno de Dança, é forma- do por uma coletânea de textos sobre processos e poéticas de- senvolvidos na companhia.


Em minha pesquisa de mestrado ${ }^{4}$ no programa de pós-graduação em Artes da Universidade Federal do Pará (PPGARTES/ ICA/UFPA), propus-me ao desdobramento dos princípios da dança imanente (imanência, metalinguagem ${ }^{5}$, visibilidade ${ }^{6}$ ). Foi utilizado como procedimento do estudo a aplicação de experimentações visando atualizar a práxis por meio da instauração de novos atravessamentos nos princípios nela já existentes.

Neste sentido, o presente artigo propõe-se a continuidade dos estudos ${ }^{7}$ em dança imanente, sublinhando questões de cunho educacional, acreditando serem estas de extrema relevância para a compreensão e amadurecimento da práxis cênica da CMD. Com efeito, são instauradas neste texto algumas considerações desta artista-pesquisadora no tocante ao que vem sendo chamando de atravessamentos educacionais na dança imanente, os quais compreendo serem inerentes a CMD, justificados em sua trajetória e nas sutilezas de seus processos criativos e formativos em dança.

A Companhia Moderno de Dança é um devir dança cujos princípios filosóficos, técnicos e metodológicos organizam-se

4 Dissertação intitulada de "Desdobrando a dança imanente: imanência, organicidade e técnica na construção de uma poética cênica", sob a orientação do professor Doutor Cesário Augusto Pimentel, 2011.

5 "Ao tecer uma analogia com a abordagem metalinguística de Avesso, é possível constatar que o recurso à metalinguagem (corpo falando/dançando sobre si) é uma estratégia da linguagem que se quer expressar por meio da dança" (MENDES, 2010, p. 217).

6 "O que vale refletir [...] é sobre o fato de [...], a visibilidade ser a etapa de formação das imagens vislumbradas pelos intérpretes-criadores, na perspectiva de respaldar teoricamente o conceito de corpo visivo" (MENDES, 2010, p. 236).

7 A continuidade dos estudos em dança imanente vem sendo motivação de minha atual pesquisa de doutorado, no PPGARTES/ICA/UFPA, onde venho me debruçando a compreender um pouco mais sobre os modus operandis da CMD como parte processual da criação de uma nova poética em dança com a companhia. como plano de imanência, agenciando conceitos comuns ao coletivo (desejo, autonomia, multiplicidade, afeto, interdisciplinaridade, descoberta, adaptação, comunidade etc). Nesta dança imanente, arte e vida confundem-se e constroem conhecimento, contribuindo para o ensino e a criação em dança em Belém do Pará, tanto no âmbito artístico e estético quanto no campo ético e social (depoimento de Ana Flávia concedido para este artigo).

Acima, o trecho de Mendes tangencia pontos caros a esta reflexão. Tais pontos observam um fazer dança por meio da interação de arte e vida, ressaltando a dependência de aspectos cuja dominante é artística daqueles relativos à sociedade e à ética. A partir do exposto, considera-se que focalizar a dança imanente como fenômeno para reflexão no campo das artes e da educação permite avanço em suas produções teórico-práticas, e potencializa o cenário das poéticas contemporâneas de dança que em muito contribuem para a construção de singularidades plurais do fazer dança no estado do Pará e no Brasil como um todo.

Como artista-pesquisadora da dança, os primeiros atravessamentos educacionais vêm me afetando desde o ano de 1997, quando os fundadores da CMD, dentre eles eu, encontraram-se pela primeira vez para iniciar as diretrizes de um trabalho nesta área no Colégio Moderno.

Moderno foi o nome de uma escola centenária da cidade de Belém do Pará - A Sociedade Civil Colégio Moderno. Considerada como vanguardista e à frente de seu tempo, foi a primeira instituição de ensino formal a admitir turmas mistas com homens e mulheres na capital paraense. Em agosto de 1997, a instituição passou a agregar em seu espaço algumas das pessoas que, 5 anos depois, seriam as responsáveis pela fundação da Companhia Moderno de Dança. 
1997 também fora o ano de meu ingresso no grupo coreográfico desta escola. A partir de então comecei a atuar no contexto artístico, por meio de uma compreensão da dança atrelada ao universo da escola e, por conseguinte, da educação formal. Inicialmente, as aulas do grupo (até meados de 2001) advinham de metodologias que instigavam o corpo dançante mais como reprodutor do movimento do que criador. Mesmo tratando-se de uma formação cujos processos de ensino e aprendizagem priorizavam momentos de cópia e repetição de movimentos advindos do professor, ali também havia espaço para a tessitura de relações da dança produzida em sala de aula com outros contextos, como o da educação.

Ao longo do tempo, amadureceu-se a compreensão de que a dança educa quem a faz e quem a frui. Os sentidos eram levados a perceberem os potenciais educativos do fazer artístico, não somente por se tratar de uma dança inserida no âmbito escolar, mas, também, pela assunção de que a educação é característica sine qua non para a dança onde quer que esteja sendo ensinada, aprendida, produzida, fruída.

Diante do exposto, expressões como "Dança Educativa" e "Dança Educação" atreladas, na maioria das vezes, ao ensino da dança na escola, passaram a perder sentido sob minhas perspectivas enquanto artista da dança, ressoando como um pleonasmo. Em nossa sociedade a escola é por excelência o espaço no qual o ser humano encontra estímulos e certos conhecimentos para transformar-se enquanto sujeito na relação com o outro, com o meio. Porém, o sentido de educação habita muitos outros espaços que não apenas o escolar, pois, segundo Porpino (2006, p. 124),

[...] constitui-se num fenômeno inerente à vida do ser humano, é multifacetada e faz parte das experiências humanas onde quer que o homem se encontre. Porém, dentre os múltiplos espaços sociais nos quais a educação se manifesta, percebemos que a escola ainda detém uma função significativa, na medida em que se destina a esse papel social. Por vezes, é percebida, equivocadamente, como único espaço realmente responsável pelo educar.

Com efeito, compreendo que em todas as diversas formas de produção e representação artística do homem, a dança encarna-se da noção de educação. A dança é educação independente de acontecer nas escolas, nos projetos sociais, em grupos da periferia, do centro da cidade, pois mesmo que não seja a dominante do trabalho, sempre educa os corpos envolvidos neste fazer.

\begin{abstract}
O despertar desse corpo pode se dar de diversas formas, não somente pela via da vivência de técnicas de sensibilização corporal, como pensávamos outrora. Uma atitude problematizadora por parte do educador torna-se imprescindível para que os alunos possam refletir sobre suas formas de danças, das danças conhecidas, do contexto em que se realizam essas danças e, mais ainda, para que possam reconhecer que além das danças já experimentadas, existem muitas outras que, como as já vividas, constituem-se em produções culturais que merecem ser respeitadas (PORPINO, 2006, p. 132).
\end{abstract}

Aos poucos fui percebendo e amadurecendo os atravessamentos da dança enquanto conhecimento com questões relativas ao contexto da educação por meio de minha própria trajetória artística na CMD, na qual atuo até os dias de hoje, e das experiências como docente no curso de Licenciatura em Dança da Universidade Federal do Pará.

Outra mola propulsora de inquietações mais próximas das argumentações por ora apresentadas foi a inserção da disciplina Escola, Dança e Educação no plano políti- 
co pedagógico do curso de Licenciatura em Dança da UFPA, ministrada pela primeira vez no $2^{\circ}$ semestre do ano de 2013. Como docente responsável pela disciplina, compartilhei com os alunos princípios da dança, tendo em vista sua constituição educacional e como a mesma se relaciona com a escola e demais contextos sociais.

$\mathrm{Na}$ condição de docente da disciplina supracitada e em outras cujo foco é a investigação de estratégias particulares para o ensino da dança nos locais onde os discentes atuam, foram propostos três projetos à universidade a fim de registrar, observar e compreender as realidades da dança no contexto escolar ${ }^{8}$ da cidade de Belém, para, a partir disto, propor, esboçar e experimentar diferentes caminhos de fazer e conhecer em dança.

Nasceu em janeiro de 2014 o projeto de pesquisa Escola, Dança e Educação: estratégias metodológicas para o ensino da dança em Belém do Pará; em agosto do mesmo ano, o projeto de extensão Escola, Dança e Educação: inserções práticas da dança na escola em Belém do Pará; e em janeiro de 2017, o projeto de extensão EDUCADANÇA: interconexões em dança no contexto escolar. Estes projetos vislumbram aprofundar os atravessamentos presentes na tríade escola, dança e educação, dentro da Licenciatura em Dança da UFPA e na comunidade belemense em geral

Em face ao exposto, o contato com a práxis da dança imanente, algumas conexões relativas às atividades na universidade e o contexto histórico da formação da

\footnotetext{
8 A parceria com as instituições formais de ensino e seus respectivos docentes de artes foi criada a partir do lançamento dos projetos de pesquisa e extensão. Os projetos se voltam para as escolas, públicas ou privadas, que possuam o ensino da disciplina Artes no seu currículo, e proporcionam espaço para a reflexão e compartilhamento dos estudos feitos com os participantes.
}

CMD, me fizeram observar atravessamentos educativos nas artes como um todo. Tais atravessamentos vêm instigando o amadurecimento de experiências, contatos e interações que se fazem e se ampliam embebidos desta possibilidade de olhar o fazer em dança imanente.

Bases Teóricas e Abordagens Metodológicas

\section{A dança imanente e seus atravessamentos educacionais}

O fazer artístico aliado a questões da educação em sentido lato corrobora para ações e concepções mais éticas, políticas e, por que não dizer, estéticas, no âmbito das produções artísticas na contemporaneidade em suas múltiplas e diversificadas linguagens. Neste sentido, "[...] abre-se a possibilidade de que processos de criação artística possam ser revistos e repensados como processos também explicitamente educacionais" (MARQUES, 2010, p. 112). Em diálogo com este pensamento, Rocha (2016, p. 30) considera que:

\begin{abstract}
Está em jogo na sala de dança o que o professor (e a professora, sempre) entende que a dança seja e ainda o que ele acredita que ela deva ser. Se ele entende a dança como uma certeza, ou uma dúvida e se ele, por exemplo, trabalha o movimento a partir da lógica do controle do vir-a-ser da dança, ou a partir da experimentação e, portanto, do manejo, de seu devir. Em pauta, o futuro da dança definido a partir do conceito de dança ali praticado, do que ele inclui e exclui. Pratica-se na aula - em qualquer aula - um pensamento de dança. Sempre.
\end{abstract}

Deste modo, é, também, no conceito, no pensamento de dança, que podem ser 
encontradas pistas das estruturas utilizadas nos processos de ensino e aprendizagem em dança, as quais afetam sobremaneira os comportamentos de todos os corpos envolvidos.

Tratar acerca de atravessamentos educacionais na dança imanente é considerar antes de tudo que questões relativas ao que se compreende por educação são constituintes deste conceito, desta práxis, atuando como motrizes dos processos vivenciados na CMD. Certos aspectos do trabalho sublinham fortemente tal assertiva.

Este artigo propõe-se não somente acrescer reflexões disparadoras acerca da dança imanente, mas, sobretudo, considerar que os atravessamentos educacionais peculiares a este fazer na CMD atuam como forças motrizes desde seu surgimento até os dias atuais, inclusive enquanto potência formativa do seu trabalho artístico em dança.

Um dos disparadores para a compreensão da noção de dança imanente trata-se do conceito de imanência, o qual "[...] não se reporta a Algo como unidade superior a qualquer coisa, nem a um Sujeito como ato que opera a síntese das coisas: é quando a imanência já não é imanência a outra coisa, que não a si, que se pode falar de um plano de imanência" (DELEUZE, 2002, p. 12). Ainda sobre esta questão, complementa:

Uma vida é a imanência da imanência, a imanência absoluta: ela é potência e beatitude completas. [...] Uma vida está por todos os lugares, por todos os momentos que atravessam este ou aquele sujeito vividos: vida imanente trazendo acontecimentos ou singularidades que apenas se atualizam nos sujeitos e nos objetos. Essa vida indefinida não tem, ela mesma, momentos [...] mas apenas entretempos, entremomentos [...]. Uma vida contém apenas virtuais. Ela é feita de virtualidades, acontecimentos, singularidades. Isso que se chama de virtual não é algo a que falta realidade, mas que se engaja num processo de atualização seguindo o plano que lhe dá sua realidade própria. $\mathrm{O}$ acontecimento imanente se atualiza num estado de coisas e num estado que faz com que ele ocorra (DELEUZE, 2002, p. 12-14.).

Em se tratando de conceber dança em companhia, na CMD percebe-se que existe um todo complexo justamente nas redes de interação tecidas pelas vidas, imanências, instauradoras do trabalho no/do/em coletivo.

A imanência congrega e sublinha questões particulares, peculiares do um, da vida. Mas o um que não é isolado e não está acabado. O um que é vários. Multiplicidade. A interação do coletivo no particular e a mão dupla que isso gera, o particular no coletivo.

Tomar como lente o conceito de imanência para refletir sobre a multiplicidade do um, vem propiciando à instigação de diferentes possibilidades de criação em dança na CMD. Para Deleuze, a imanência encontra-se no plano de imanência que conecta todas as coisas vivas e que por esse motivo não está contido dentro de um corpo, aprisionado ou em função de um objeto, mas relacionado aos seres vivos, cortando-os, atravessando-os, tornando-os simples e absolutamente, imanência.

A imanência enquanto vida sugere constante relação com os corpos, refletindo neles nada mais que estados de vida. Estados inconclusos, transitórios. Podemos pensar que a imanência enquanto vida também afeta e interfere o estado de transitoriedade de todo e qualquer corpo existente, onde tudo se relaciona dentro do plano de imanência, sem conclusões, sempre em estado de inacabamento, de devir.

Ao sugerir uma visão de mundo onde as coisas encontram-se em relação e inacabadas, observo que a noção de imanência aplicada à dança abre espaço para um sentindo amplo sobre a educação, posto que é 
vista como inerente à própria existência humana na medida em que "É na inconclusão do ser, que se sabe como tal, que se funda a educação como processo permanente. Mulheres e homens se tornam educáveis na medida em que se reconheceram inacabados" (FREIRE, 1996, p. 58). A esse respeito, compreende-se que,

\begin{abstract}
É a partir desse inacabamento, desta riqueza existencial e suas infinitas possibilidades que a educação, fenômeno tipicamente humano, torna-se possível. Aprendemos, educamo-nos porque somos seres inacabados, incompletos e temos consciência desse inacabamento, da abertura infinita ao aprimoramento, ao ser mais. (TROMBETTA; TROMBETTA, 2010, p. 222).
\end{abstract}

Se imanência se refere à vida, por inferência, observa-se que o corpo humano é ele próprio imanência. $\mathrm{Na}$ qualidade de ser uma vida e nada mais, atravessa o sujeito vivido, isto é, o corpo ao ser atravessado de imanência, por sua capacidade de afetar e ser afetado, também afeta outros corpos segundo a própria vida que nele se atualiza. Corpo imanência, corpo imanente, vida. Tão imanência porque encharcado de imanências e construtor de imanências.

A aplicação da noção de imanência na operação de um pensamento em dança na CMD também promove a construção de uma práxis explicitamente educativa no tocante à assunção da ausência de hierarquia entre os corpos. De tal feita, ocorre a percepção da dependência, do cuidado, da escuta, da partilha sensível que se encontra principalmente nas fendas, no trânsito, na ignorância, na incompletude presente no trabalho em arte deste coletivo.

Considero que a lida na CMD pulsa inventando suas tensões nos cruzamentos, no trânsito, nos nós que se laçam, nos afetos, nas forças, cada ponto deste metaforizado aqui como sendo as imanências, os corpos artistas da Companhia Moderno de Dança.

\begin{abstract}
No que tange ao campo artístico... um complexo tesouro é que a construção de laços antigos (com pessoas que já não estão em companhia) faz com que a generosidade, o cuidado, a atenção e a necessidade de endossamento desses laços sejam vistos como interpenetrados para o fazer artístico... Especificamente da cena. Com relação ao campo físico-afetivo... um tesouro é: as memórias dos gestos, do toque, do cheiro, da voz da pessoa...do mais antigo ao mais novo...e daqueles que fizeram parte... essas memórias funcionam como elemento que conecta os afetos por cada um...imprimindo uma relação específica na cena e fora dela (em especial, fora dela) e também imprimindo uma necessidade de relacionar-se.
\end{abstract}

O depoimento acima, concedido para este artigo, é de Andreza Barroso, uma das bailarinas da companhia. Dentre outros aspectos, suas considerações impregnam-se de uma intensa implicação entre as dimensões da vida e da arte, as quais permitem observarmos questões em educação para além de formalismos e estruturas estritamente relativos aos contextos já consagrados para este fim.

Como anteriormente dito, a dança imanente foi cunhada inspirada na noção de imanência, imbricada nos estudos de doutorado de Ana Flávia. Naquele tempo a artista criou o termo como metodologia da poética do espetáculo Avesso, objeto de sua pesquisa. "Os modos operacionais do espetáculo apontaram os procedimentos criativos instaurados na construção do mesmo, sendo este, portanto, o nascedouro da dança imanente" (MENDES, 2016, p. 2096).

Mesmo embrionariamente enquanto metodologia já apontava atravessamentos potentes relativos à educação, pois, "Não se trata apenas de uma metodologia de criação 
artística, mas de uma estratégia interdisciplinar de educação e descoberta de soluções para a vida por meio da dança". (MENDES, 2010, p. 338).

Como poética de Avesso, a dança imanente propunha uma metodologia para 0 agenciamento das características e caminhos daquele processo de criação, os quais focavam prioritariamente o corpo como celeiro para a criação do movimento em dança.

Estamos diante da busca por uma dança do próprio corpo, aberto, agenciador $\mathrm{e}$ inacabado, que tem em si mesmo todas as potências daquilo que o circunscreve, inclusive outros corpos. Em suma: para a dança imanente, o corpo é o "eu”, mas é também o 'outro'. (MENDES, 2016, p. 2098).

Aquele processo ampliava na CMD os caminhos que davam vazão ao corpo dotado de múltiplas possibilidades na construção do movimento a partir de si e suas relações com outros corpos: um corpo autônomo na dança. "O respeito à autonomia e à dignidade de cada um é um imperativo ético e não um favor que podemos ou não conceder uns aos outros". (FREIRE, 1996, p. 59).

O percurso de amadurecimento da autonomia do corpo na formação artística em dança na CMD também sublinha atravessamentos de cunho educacional instaurados por meio da dança imanente. Pode-se, então, convocar a máxima de "Saber que ensinar não é transferir conhecimento, mas criar as possibilidades para a sua própria produção ou a sua construção". (FREIRE, 1996, p. 47). Coadunando ao exposto, é importante acrescentar que

Técnica e estética se entrelaçam de modo muito apertado no ensino de arte. Está em jogo mais uma vez que grau de negociação é permitido na relação entre o que se ensina e o que se aprende e o quanto o professor está disposto ou não a educar, ou seja, a desenvolver expedientes para tornar-se pouco a pouco dispensável, ensinando ao aluno a prescindir dele, professor, e a imprescindir de si. Fomentar no aluno sua autonomia, correlata ao responsabilizar-se por si, significa aceitar como princípio a descontinuidade intrínseca ao ato de aprender implícita na máxima da educação contemporânea que afirma: não é o professor que ensina, mas o aluno que aprende. Nesta descontinuidade, a possibilidade da formação de um criador-pensador em dança. (ROCHA, 2016, p. 33).

Atualmente um dos princípios primordiais durante as imersões nos processos criativos na CMD é a possibilidade de operacionalização da criação a partir do corpo criador, e não apenas como suporte de criações de um coreógrafo. Deste modo,

Como pedir de um intérprete que ele crie, que ele escolha, tendo passado anos de sua vida em uma sala de aula de dança, alienado dos devires do mundo e dos devires estéticos da arte, sendo muitas vezes ostensivamente humilhado e desinvestido da intimidade de seu próprio movimento, fazendo de seu corpo, e de si um instrumento? Se lhes ensinarmos a fazer passos e não a escolher, provavelmente estamos roubando-Ihes correlativamente, por mais contraditório que possa parecer, a possibilidade de dançar. Até que ponto estamos dispostos a admitir o artista-em-formação como um agente autônomo e responsável que escolhe e decide? Este ponto será o limite vivido futuramente pelo intérprete na assunção autônoma e criativa de sua responsabilidade em decidir kinestesicamente quando dança. (ROCHA, 2016, p. 52).

Em diálogo com o pensamento de Rocha, ressalto que foi em Avesso onde Ana Flávia começou a se dar conta que "a dança diferente", que almejava quando iniciou na área da docência, encontraria espaço por meio do estímulo à autonomia dos próprios corpos dançantes da companhia, ou seja, na 
descoberta de uma dança do um, do entre, da vida, de um pensamento de dança do(s)/ no(s)/para o(s) corpo(s) que dança(m). Sublinho novamente percepções de que a dança imanente já iniciava um percurso atravessada da ideia de educação, a qual, segundo a autora, seria possível de alterar processos artísticos e formativos do homem.

É por isso que reconheço, [...], a real possibilidade de difusão desta poética da dança imanente como uma maneira de fazer com predicados de prática artístico-pedagógica, assim como idealiza Izabel Marques (2001) em sua dança centrada no contexto. Sinto que tudo isso que a CMD vem construindo não é para uso próprio, mas sim para o aproveitamento de outros, com fins de investir em formação cidadã (MENDES, 2010, p. 339).

Foco de estudo nos processos criativos da companhia, em pesquisas acadêmicas (dentre as quais cito meu doutorado), e compartilhando espaços em contextos não acadêmicos, a dança imanente vem adquirindo novos contornos. Passou não somente a refletir as características de uma poética como a assumir-se enquanto práxis artística da CMD.

Ao propor que o corpo na dança é imanência, Ana Flávia inaugurou ainda o conceito de corpo imanente, o qual tece conexões com todas as relações operantes nas bordas, fendas, "dentro", "fora" do corpo no início, meio e fim do processo de criação. Com efeito, "A dança imanente é, como o próprio adjetivo retrata, uma dança de imanências, de multiplicidades. A imanência é o dançarino. $O$ dançarino é o seu mundo e este mundo, um plano de imanência" (MENDES, 2014, p. 13).

Os compartilhamentos coletivos presentes no trabalho da companhia como um todo são também reflexos dos atravessamentos educacionais tratados neste artigo.
O fazer com, em companhia, tem sido uma das maiores marcas na trajetória do grupo, das mais moventes,

Logo nos anos iniciais, as escolhas estéticas constantemente espelhavam-se na figura tradicional do coreógrafo(a) (aquele que tem a função de criar os movimentos para a coreografia) que, naquele momento, era Ana Flávia. A diretora contava que um de seus maiores sonhos era descobrir uma "dança diferente", nunca dançada, nunca vista. Aos poucos, o que figurava como uma quimera foi se materializando nas condições geradas pelo processo, no tocante à relação da coreógrafa com os próprios bailarinos, consolidando-se principalmente no período onde foram levantados os primeiros questionamentos relativos à dança imanente.

Talvez não tenha havido uma escolha de "descentralização criativa" da coreógrafa para os bailarinos (que aos poucos passaram a criar o(s) movimento(s)/dança(s)), pois tudo foi muito intuitivo e progressivamente ganhou maturidade nas poéticas do grupo. Foi-se percebendo que quanto mais coletiva, compartilhada, a criação era, mais diversa ela seria. De estímulo a estímulo, processo a processo. O(s) movimento(s)/ dança(s) seria $(\mathrm{m})$ muito mais diverso(s), múltiplo(s), inusitado(s), quanto mais pessoas pudessem experimentar, conceber, gestar.

Estar com, compartilhar, dividir tessituras de vida e tecê-las juntas demanda grandes esforços, afetos e grandes responsabilidades, ainda mais em se tratando de uma partilha de vida e arte onde "O querer bem ao outro, tão necessário ao aprendizado do diálogo, implica antes de qualquer coisa um querer bem de modo genérico à vida, implica um estar no mundo e saber-se pertencente a ele, implica um sentir-se vivo, simplesmente". (DOWBOR, 2008, p. 74). 
Para além da responsabilidade na lida com o outro, dos limites que relações em companhia demandam, é importante reiterar que se trata de um coletivo artístico. A ênfase chama atenção ao fato de que o primeiro objetivo em comum de todos os companheiros desta companhia é o fazer dança. No entanto, não há como descolar as tessituras de vida individuais das tessituras vividas com o outro.

Ao propor o diálogo do corpo com o próprio corpo e outros corpos, a dança imanente assume posturas éticas do fazer dança. Instiga caminhos de ruptura possíveis para o corpo, para o movimento, para a dança, para a educação, partindo do entendimento de que qualquer pessoa pode dançar e, portanto, construir conhecimento em dança. Observa-se, assim, que esta práxis agencia experiências e princípios sobre movimento, corpo e dança muito particulares do contexto artístico da CMD, mas que também podem ser aplicados a outros contextos para a produção em dança/arte na contemporaneidade.

É importante considerar, ainda, que atravessamentos educacionais constituintes do fazer da dança imanente alicerçados em experiências artísticas promotoras de autonomia, produção de conhecimento, partilha de saberes, assunção de inacabamento, dentre outras, são instauradores dos corpos imanentes da companhia, incitando a percepção da multiplicidade de agenciamentos possíveis destes corpos nas infinitas relações de serem e estarem no mundo, inclusive por meio da arte da dança.

As peculiaridades desta práxis instauram o corpo criador encharcado de potenciais educativos na formação e produção artística em diversas esferas, como a esfera do corpo criador para com ele mesmo; do corpo criador para com os outros corpos pelos quais é atravessado em processos artís- ticos-formativos; do corpo criador para com o público fruidor da obra etc. Em consonância a este pensamento, Vecchia (2010, p. 27) afirma que

\begin{abstract}
[...] o homem se torna liberto à medida que for capaz de ser autônomo, assumir a decisão pela mudança de si e da sociedade, através da educação permeada pela afetividade, pelo diálogo, pelo questionamento, pela conscientização oriunda de um processo comunitário, solidário e integrado de abordagem da realidade e do engajamento efetivo na mudança. Tudo se origina de um sentir a realidade, um pensar sobre este sentir e uma ação consequente e engajada.
\end{abstract}

$\mathrm{Na}$ dança imanente encontra-se uma íntima conexão dos processos de criação com mecanismos flexíveis e múltiplos capazes de possibilitar um (re)conhecimento do corpo que dança em relação a si e ao outro por meio da noção de experiência. Tal assertiva ratifica mais uma vez sua potência educativa considerando, também, que propõe como procedimentos artístico-formativos experiências de ensino e aprendizagem não fixadas em estruturas hierárquicas para produção e apreensão do conhecimento em dança. Estas experiências não instauram noções tradicionais e dicotômicas sobre o corpo e investem na multiplicidade e na indeterminação dos processos criativos como celeiro de partilhas sensíveis e coletivas, construídas por meio de saberes e de sujeitos da experiência.

A experiência é o que nos passa, o que nos acontece, que nos toca. Não o que se passa, não o que acontece, ou o que toca. A cada dia se passam muitas coisas, porém, ao mesmo tempo, quase nada nos acontece. Dir-se-ia que tudo o que se passa está organizado para que nada nos aconteça. Walter Benjamin, em um texto célebre, já observava a pobreza de experiências que caracteriza o nosso mundo. Nunca se passaram tantas coisas, mas a expe- 
riência é cada vez mais rara (BONDÍA, 2002, p.21).

A dança imanente, então, vem promovendo espaços de experiência artística, priorizando o bailarino como o próprio sujeito da experiência. Não como aquele que precisa fazer, fazer e fazer sem que nada se passe. Mas como alguém que se coloca em passividade para que as experiências aconteçam. Pois,

[...] seja como território de passagem, seja como lugar de chegada ou como espaço do acontecer, o sujeito da experiência se define não por sua atividade, mas por sua passividade, por sua receptividade, por sua disponibilidade, por sua abertura Trata-se, porém, de uma passividade anterior à oposição entre ativo e passivo, de uma passividade feita de paixão, de padecimento, de paciência, de atenção, como uma receptividade primeira, como uma disponibilidade fundamental, como uma abertura essencial (BONDÍA, 2002, p. 24).

\section{Considerações}

Diante do exposto, percebo que as reflexões por ora apresentadas sublinham que os atravessamentos educacionais da dança imanente são motrizes que encharcam os corpos dançantes antes, durante e depois de processos de formação e criação, e que impregnam, evidentemente, as obras e as vidas ali presentes, isto é, operam como imanências que afetam os corpos-imanências da Companhia Moderno de Dança, fazendo com que esta práxis seja educativa.

Por fim, ao desenvolver as considerações apresentadas nesta escrita, desejo ratificar que a dança imanente está investida das dominantes artística e educativa, constituindo-se de potências sem as quais não pode ser compreendida e praticada.
Uma educação plural, educações possíveis, construtoras de caminhos. Educação em dança como atravessamento e não como acessório, opção, escolha. Educação sendo ela mesma imanência, operando como força que garante vida ao devir dança em suas diversas camadas na contemporaneidade.

Sem desejar encerrar os caminhos para onde estas reflexões podem levar, observo que contribuem, dentre outros aspectos, para o amadurecimento nos estudos desenvolvidos a respeito da dança imanente, compreendendo que atravessamentos que perpassam a história da CMD, e aqueles que se cruzam, conectam e afetam os que percorrem minha própria trajetória artística, são geradores e instauradores dos princípios que vêm corroborando na maturação do trabalho e referenciais epistemológicos na rede da dança imanente. Assim, compartilho das quimeras de Mendes (2010, p. 342) ao dizer que

\begin{abstract}
Tudo parte de uma necessidade de criar e encenar dança permeada por valores estéticos diferenciados, sem a preocupação em seguir princípios e procedimentos vigentes em outras poéticas ou metodologias coreográficas. Muito mais que isso, no entanto, tudo parte da construção de uma aspiração que se pretende realizar, de uma quimera que se quer efetivar, de uma visibilidade de mundo que se quer visível nos homens por meio da arte do movimento. cênico.
\end{abstract}

Referências

BONDÍA, Jorge Larrossa. "Notas sobre a experiência e o saber da experiência." In: Revista Brasileira de Educação. $\mathrm{N}^{\circ}$ 19. Jan/ Fev/Mar/Abr. 2002. 
DELEUZE, Gilles. "A imanência: uma vida." In: Revista Educação e Realidade, V. 27, N.2, p. 10-18, jul/dez, 2002. Rio Grande do Sul. Disponível em: http://seer.ufrgs.br/index. php/educacaoerealidade/article/view/31079. Acessado em: 11.05.2011.

DOWBOR, Fátima F. Quem educa marca o corpo do outro. São Paulo. Cortez editora. 2008.

FREIRE, Paulo. Pedagogia da autonomia: saberes necessários à prática educativa. São Paulo: Paz e Terra, 1996.

MARQUES, Isabel. Linguagem da dança: arte e ensino. São Paulo: Digitexto, 2010.

MENDES, Ana Flávia. Dança imanente: uma dissecação artística do corpo no processo de criação do espetáculo Avesso. Coleção Processos Criativos em Companhia - Volume 2. São Paulo: Escrituras, 2010.

A dança imanente no ensino e criação em artes cênicas. Resultado final de estágio de pós-doutorado desenvolvido junto ao Programa de Pós-graduação em Artes Cênicas da Universidade Federal do Estado do Rio de Janeiro. Supervisão: Profa. Dra. Enamar Ramos. Rio de Janeiro, 2014.

Coreofotografia: a sacralização do corpo que dança. In: Anais do IX Congresso da ABRACE. 2016.

PORPINO, Karenine de Oliveira. Dança é educação: interfaces entre corporeidade e estética. Natal, RN: EDUFRN - Editora da UFRN, 2006.
ROCHA, Thereza. O que é dança contemporânea?: uma aprendizagem e um livro de prazeres. Salvador: Conexões Criativas, 2016.

TROMBETTA, Sergio; TROMBETTA, Luis Carlos. "Inacabamento." In: STRECK, Danilo R, REDIN, Euclides, ZITKOSKI, Jaime José (organizadores). Dicionário Paulo Freire. Belo Horizonte: Autêntica Editora, 2010. pp. 221-222.

VECCHIA, Agostinho Mario Dalla. "Afetividade." In: STRECK, Danilo R, REDIN, Euclides, ZITKOSKI, Jaime José (organizadores). Dicionário Paulo Freire. Belo Horizonte: Autêntica Editora, 2010. pp. 221-222.

Recebido: 08/02/2019 Aprovado: 16/07/2019 